\title{
Deactivation without explantation of a durable left ventricular assist device: A durable solution?
}

\author{
Francis D. Pagani, MD, PhD
}

\author{
From the Department of Cardiac Surgery, University of Michigan, Ann Arbor, Mich. \\ Disclosures: Author has nothing to disclose with regard to commercial support. \\ Received for publication Oct 14, 2017; accepted for publication Oct 24, 2017; available ahead of print Nov 01, \\ 2017. \\ Address for reprints: Francis D. Pagani, MD, PhD, Department of Cardiac Surgery, University of Michigan, 5161 \\ Cardiovascular Center, SPC 5864, 1500 E Medical Center Dr, Ann Arbor, MI 48109 (E-mail: fpagani@umich. \\ edu). \\ J Thorac Cardiovasc Surg 2018;155:655-6 \\ $0022-5223 / \$ 36.00$ \\ Copyright (c) 2017 by The American Association for Thoracic Surgery \\ https://doi.org/10.1016/j.jtcvs.2017.10.064
}

Implantation of a durable left ventricular assist device (LVAD) now exceeds heart transplantation as the most common surgical procedure for treatment of advanced heart failure. ${ }^{1}$ There are increasing circumstances during durable LVAD support in which deactivation of the device is sought as an alternative to continued mechanical circulatory support. These include (1) deactivation after myocardial recovery; (2) treatment of complications of device support, such as device-related infection or thrombosis, in the setting of partial or full myocardial recovery; and (3) to respect the wishes of the patient or family to discontinue mechanical circulatory support as a consequence of poor quality of life. Device deactivation with pump explantation is a major procedure that carries the potential for significant risk, and alternative means of pump deactivation without explantation have been reported with minimally invasive surgical or percutaneous techniques. ${ }^{2}$ In this issue of the Journal, Kidambi and colleagues ${ }^{3}$ report on a novel approach to pump deactivation that uses a minimally invasive catheter-based technique in which an Amplatzer Vascular Plug (St Jude Medical, St Paul, Minn) is positioned within the outflow graft of the LVAD to prevent retrograde flow into the left ventricle after termination of pump support. $\mathrm{Pa}-$ tient follow-up at 9 months suggests durability of the result, with no untoward adverse events.

The approach described by Kidambi and colleagues ${ }^{3}$ is simple, is easily applied, and serves as an alternative to complete pump explantation or device deactivation through alternative minimally invasive surgical approaches, including upper right anterior thoracotomy or a subxiphoid approach to tie off the outflow graft. The issue here is not the technical aspects of the procedure, however, but rather when and how to apply this approach to obtain the best outcome for the patient. Obviously, in situations in which device deactivation is driven by quality of life issues or expected poor survival, the use of such a technique affords the patient the least risk of adverse events and greatest comfort in the setting of limited survival. The issue becomes more complex for younger patients undergoing device deactivation in response to involvement. device explantation.

\section{References}

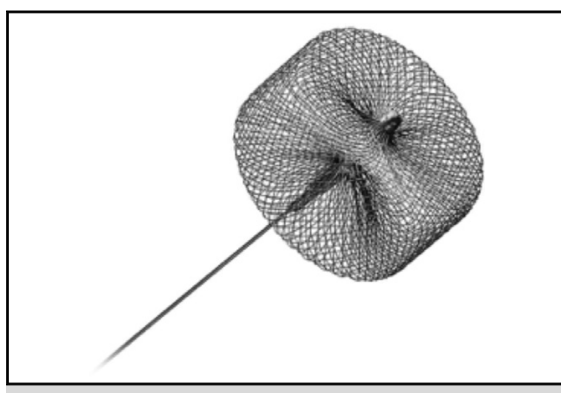

Durable LVAD deactivation with insertion of a vascular plug into the outflow graft.

\section{Central Message}

A minimally invasive catheter-based technique to deactivate a durable left ventricular assist device without device explantation is an alternative to minimize risks of operative device explantation.

See Article page 653.

myocardial recovery, for whom leaving a durable device implanted does pose a risk of thromboembolism and infection, the results of which are not well characterized by data from large studies. Important issues, such as the best technique to deal with the percutaneous lead to prevent subsequent infection, are not well described, and whether leaving a device implanted leaves some degree of pericardial constriction, impairment of right ventricular function, or impairment of the twisting mechanics of the left ventricle has also not been studied in sufficient detail. Most important is the scenario of deactivation in the setting of percutaneous lead infection. The issue of importance here is ensuring that all portions of the infected percutaneous lead have been removed and that there is no evidence of remaining ascending infection of the percutaneous lead or mediastinal

Kidambi and colleagues ${ }^{3}$ have provided another tool in the arsenal to address durable LVAD deactivation. As with many novel ideas, further data will be needed to validate the technique's durability and the optimal circumstances in which it is applied as an alternative to operative

1. Kirklin JK, Naftel DC, Pagani FD, Kormos RL, Stevenson LW, Blume ED, et al Seventh INTERMACS annual report: 15,000 patients and counting. J Heart Lung Transplant. 2015;34:1495-504. 
2. Pendyal A, Chien CV, Mudd JO, Gelow JM. Minimally invasive LVAD deactivation in a 65-year-old man with recurrent pump thrombosis and left ventricular recovery. Texas Heart Inst J. 2017;44:70-2.
3. Kidambi S, Shudo Y, Dake MD, Woo YJ, Ha RV. Percutaneous, minimally invasive approach to implantable left ventricular assist device deactivation. J Thorac Cardiovasc Surg. 2018;155:653-4. 